Full Paper

\title{
Characterization and Application of Bismuth-Film Modified Carbon Film Electrodes
}

\author{
Rasa Pauliukaite, Christopher M. A. Brett* \\ Departamento de Quimica, Universidade de Coimbra, 3004-535 Coimbra, Portugal \\ *e-mail: brett@ci.uc.pt
}

Received: December 23, 2004

Accepted: February 21, 2005

\begin{abstract}
Bismuth film electrodes, formed by electrochemical deposition on carbon film resistor electrode substrates at constant applied potential, by potential cycling or at constant applied current have been investigated for the first time. The electrochemical behaviour of the films was characterised by cyclic voltammetry and electrochemical impedance spectroscopy and they were applied to the determination of $\mathrm{Zn}, \mathrm{Cd}$, and $\mathrm{Pb}$ by square-wave anodic stripping voltammetry. The highest sensitivities coupled with nanomolar detection limits were achieved at bismuth films formed at constant potential; however, in situ deposited bismuth films exhibited better reproducibility. Future application as small, short-term-use sensors is indicated.
\end{abstract}

Keywords: Bismuth films, Carbon film electrodes, Trace metal determination, Stripping voltammetry, Electrochemical impedance spectroscopy

Devoted to the Memory of Professor Robert (Bob) Osteryoung

\section{Introduction}

Since the year 2000, bismuth film electrodes (BiFEs) have become an attractive new subject of electroanalytical research as a potential replacement for mercury electrodes [1]. Bismuth films have been deposited on carbon substrates, particularly on glassy carbon [1-13], carbon fibre [1, 8], screen-printed electrodes $[14,15]$, carbon paste electrodes $[8,16-19]$, electrically heated carbon paste electrodes [20], and boron-doped diamond electrode [19], showing excellent advantages with respect to mercury films. Bismuth bulk electrodes have also been studied and compared with BiFEs [21]. The films were deposited electrochemically at constant potential either in situ (in the model or sample solution) $[1,3-5,7,8,10,14-16,19,22-24]$ or ex situ by predeposition $[2,6,9,11-13,20,25-28]$.

In most cases bismuth film electrodes were characterized using voltammetry $[4,13]$ and microscopy $[1,12,13,29]$ and the results obtained showed that the bismuth film is essentially uniform. The most common application of the bismuth film electrode has been in the determination of trace metals, in particular by anodic $[1,3-5,8-10,14,17-$ $20,22-24]$, cathodic [19], adsorptive stripping voltammetry $[2,11,13,22,25,26,28]$, potentiometric stripping analysis [7, 16] and chronopotentiometry [15] as well as in sonoelectroanalysis [12]. Apart from metals, some organic compounds have been analysed, such as 2-nitrophenol and bromophenoxim by cyclic voltammetry and chronoamperometry in batch [6] and flow injection mode [28].

Carbon film electrodes fabricated from carbon film electrical resistors have recently been developed and evaluated [30-32]. They have a wider potential range than many other forms of carbon electrode, especially after surface pretreatment; other advantages are physical robustness and ease of preparation. Use as short-term or disposable sensors for trace metals [30,33], as an ascorbate sensor [34], characterization with mediator coatings [35] and as support for enzyme biosensors [36-38] has been demonstrated.

In this work, bismuth films have been electrochemically deposited onto these carbon film resistor electrodes by different methods, in order to assess the benefits of bismuth films in the negative potential range compared to bare carbon films. Besides ex situ and in situ deposition at constant potential, electrode potential cycling in the negative potential region was used as well as ex situ deposition at constant current. The films obtained were characterized by cyclic voltammetry and electrochemical impedance spectroscopy. Square-wave voltammetry has been demonstrated to be an excellent technique for the measurement and characterization of processes involving trace metal ions [39]. At these BiFEs, the square-wave anodic stripping voltammetric response to zinc, cadmium and lead ions is successfully demonstrated and evaluated.

\section{Experimental}

\subsection{Chemicals and Solutions}

Bismuth(III) nitrate, lead(II) nitrate, cadmium(II) chloride, and zinc(II) chloride were from Sigma (Germany). Sodium 
acetate and acetic acid (Riedel-de Haën, Germany) and Millipore Milli-Q nanopure water were used to prepare $0.1 \mathrm{M}$ acetate buffer, $\mathrm{pH}$ 4.45. Stock solutions of the salts mentioned above, concentration $1 \mathrm{~g} \mathrm{~L}^{-1}$, were prepared in acetate buffer and stored at room temperature. They were diluted as required before measurements. Experiments were carried out at room temperature $\left(25 \pm 1^{\circ} \mathrm{C}\right)$.

\subsection{Instrumentation and Methods}

A three-electrode cell was used for voltammetric measurements, containing a Bi-coated carbon film working electrode, a platinum foil counter electrode and a saturated calomel electrode (SCE) as reference. Preparation of the carbon film electrodes from $2 \Omega$ carbon film electrical resistors is described in Ref. [30]. These consist of ceramic cylinders, length $0.6 \mathrm{~cm}$ and diameter $0.15 \mathrm{~cm}$ on which carbon is deposited by pyrolysis, with gold-coated metal contact caps and connecting wires at each end. One of the metal contacts with connecting wire is removed, and the other covered with a plastic sheath and epoxy resin leaving an area of ca. $0.20 \mathrm{~cm}^{2}$ exposed. Electrodes were pretreated in acetate buffer by potential cycling from -1.5 to $1.5 \mathrm{~V}$ vs. SCE 10 times before first use.

Square-wave and cyclic voltammetry measurements were performed using a computer-controlled $\mu$-Autolab Type II potentiostat/galvanostat with GPES 4.9 software (Eco Chemie, Netherlands). For square-wave anodic stripping voltammetry (SWASV) the frequency was $25 \mathrm{~Hz}$, step potential $4 \mathrm{mV}$, and amplitude $25 \mathrm{mV}$; the potential was swept from -1.4 to $-0.4 \mathrm{~V}$ (vs. SCE), after an equilibration time of $15 \mathrm{~s}$.

Electrochemical impedance measurements were carried out in the same electrochemical cell with a PC-controlled Solartron 1250 frequency response analyzer coupled to a Solartron 1286 electrochemical interface using ZPlot 2.4 software (Solartron Analytical, UK). A sinusoidal voltage perturbation of amplitude $10 \mathrm{mV}$ was applied, scanning from $65 \mathrm{kHz}$ to $0.1 \mathrm{~Hz}$ with 10 points per frequency decade, auto-integration time $90 \mathrm{~s}$. Fitting to electrical equivalent circuits was performed with ZView 2.4 software.

\subsection{Formation of Bismuth Films}

Bismuth films were formed by deposition onto the carbon substrate in different ways:

i) At constant applied potential. Films were deposited at $-1.4 \mathrm{~V}$ (vs. SCE) for $300 \mathrm{~s}$ from a solution containing $1 \mathrm{mg}$ $\mathrm{L}^{-1} \mathrm{Bi}(\mathrm{III})$ in $0.1 \mathrm{M}$ acetate buffer, $\mathrm{pH}$ 4.45. The electrode was previously held at $+0.3 \mathrm{~V}$ for 5 min to re-oxidize any heavy metal species present at the electrode surface, and the solution was stirred during conditioning and during deposition. Films were either predeposited ex situ in a different solution from that used for characterization or for measurement of trace metals or in situ together with the trace metal ions.

Electroanalysis 2005, 17, No. 15-16 ii) By potential cycling in a solution containing $100 \mathrm{mg} \mathrm{L}^{-1}$ $\mathrm{Bi}(\mathrm{III})$ in $0.1 \mathrm{M}$ acetate buffer, $\mathrm{pH} 4.45$. The potential was swept between -1.4 and $-0.3 \mathrm{~V}$ vs. SCE) for 20 cycles at a sweep rate of $50 \mathrm{mV} \mathrm{s}^{-1}$. The electrode was then taken out of the deposition solution and rinsed with distilled water.

iii) By galvanostatic deposition in $0.1 \mathrm{M}$ acetate buffer solution, $\mathrm{pH} 4.45$, containing $100 \mathrm{mg} \mathrm{L}^{-1} \mathrm{Bi}$ (III) and applying a current of $-10 \mathrm{~mA} \mathrm{~cm}^{-2}$ for $300 \mathrm{~s}$.

The metals to be analyzed by square-wave anodic stripping voltammetry (SWASV) were deposited at $-1.4 \mathrm{~V}$ $(\mathrm{Zn})$, and $-1.2 \mathrm{~V}(\mathrm{Cd}, \mathrm{Pb})$ (vs. SCE) for $120 \mathrm{~s}$ and the electrode equilibrated after deposition for $15 \mathrm{~s}$. The solution was stirred during the whole deposition time.

\section{Results and Discussion}

\subsection{Electrochemical Characterization of the Bismuth Film Eelectrodes}

\subsubsection{Potential Window}

BiFEs exhibit a wider negative potential window than carbon film electrodes in the negative range, but cannot be used in the positive potential region due to re-oxidation of $\mathrm{Bi}$ itself [1]. Figure 1 shows the negative limit of the potential window in $\mathrm{pH} 4.45$ acetate buffer of a bare carbon film and of a bismuth-coated electrode, following deposition at a constant potential of $-1.4 \mathrm{~V}$ for $300 \mathrm{~s}$. Under these conditions, the negative potential limit of the carbon film was about $-1.4 \mathrm{~V}$ (vs. SCE), similar to that obtained in [30, 31] after pretreatment in $0.1 \mathrm{M} \mathrm{HClO}_{4}$ electrolyte. A more negative potential limit, of approximately $-1.6 \mathrm{~V}$, was obtained at the bismuth film. Bismuth films deposited in situ and ex situ at $-1.4 \mathrm{~V}$ exhibit a similar potential window, as would be expected, since the only difference is the presence of $\mathrm{Bi}(\mathrm{III})$ in solution in the former case.

Bismuth films deposited by cycling of the electrode potential and galvanostatically, following the procedure

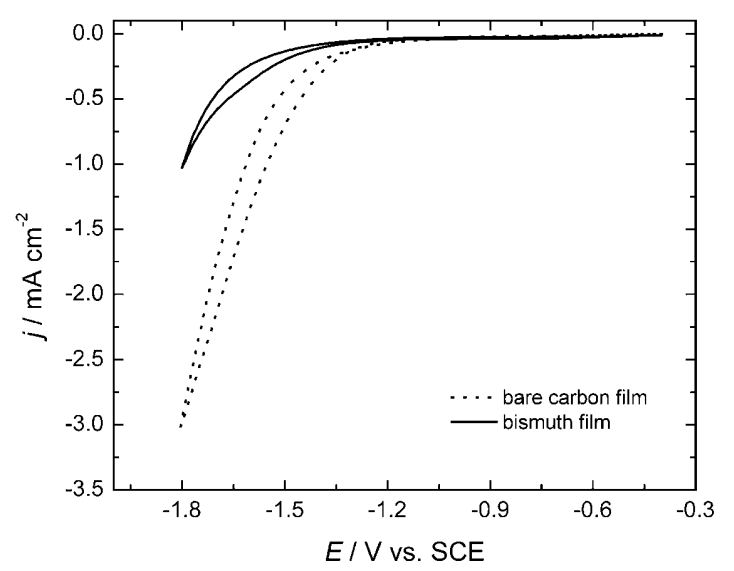

Fig. 1. Cyclic voltammograms at bare carbon film electrode and bismuth film electrode, formed ex situ at constant potential, in $0.1 \mathrm{M}$ acetate buffer, $\mathrm{pH} 4.45$, sweep rate $50 \mathrm{mV} \mathrm{s}^{-1}$. 
(a)
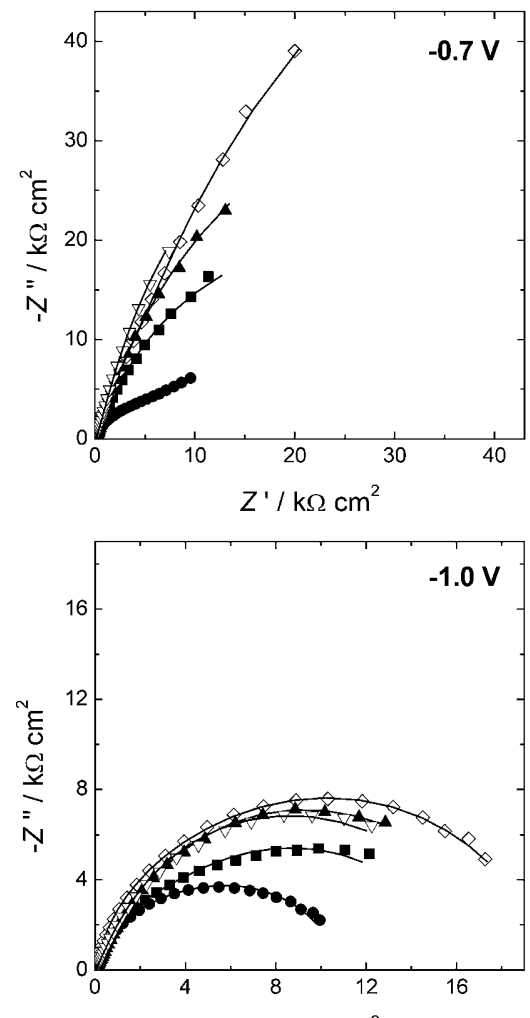

$Z^{\prime} / \mathrm{k} \Omega \mathrm{cm}^{2}$

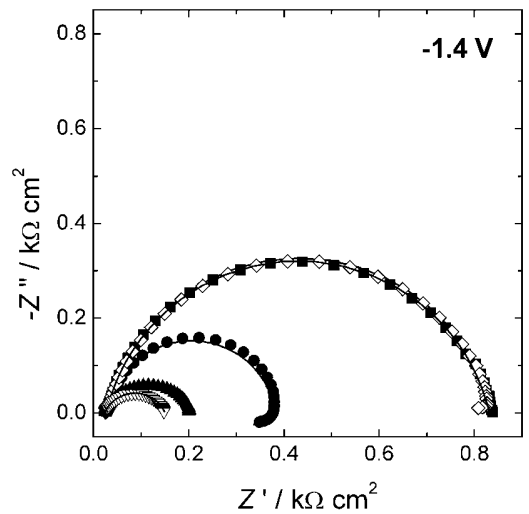

(b)
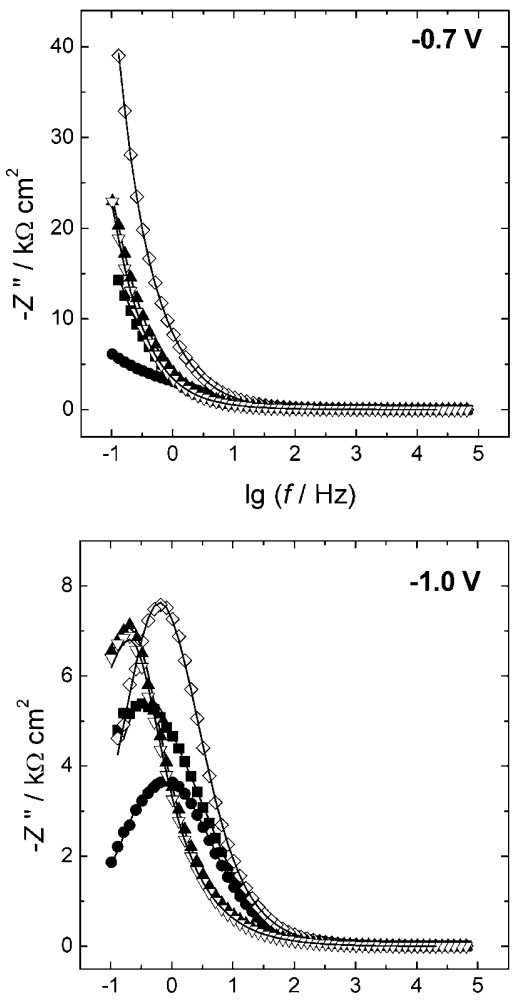

$\lg (f / \mathrm{Hz})$

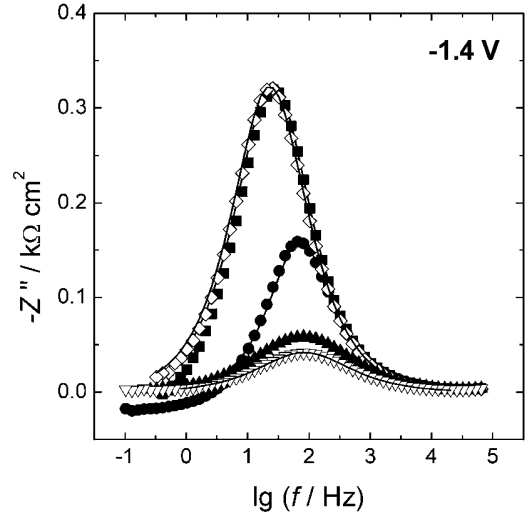

Fig. 2. Electrochemical impedance spectra: (a) complex plane (b) imaginary part vs. frequency at bare carbon film (•) and at bismuth films formed at constant potential $(\bullet)$ ex situ and $(\diamond)$ in situ, $(\nabla)$ by potential cycling and $(\boldsymbol{\wedge})$ galvanostatically. The lines show the results of fitting. Supporting electrolyte $0.1 \mathrm{M}$ acetate buffer, $\mathrm{pH} 4.45$.

described in the experimental section, had a less wide potential window, closer to that of the bare carbon film.

The more negative potential limit obtained by constant potential deposition is better suited to the determination of zinc, as will be shown below.

\subsubsection{Electrochemical Impedance Spectra}

Figure 2 shows impedance spectra recorded at bare carbon electrodes and at BiFEs deposited in different ways at applied potentials of $-0.7 \mathrm{~V},-1.0 \mathrm{~V}$ and $-1.4 \mathrm{~V}$ as plots (i) in the complex plane and (ii) with the imaginary part, $Z$ ", as a function of frequency. The latter type of plot represents a powerful way of examining the time constants of interfacial processes, since the peaks in the plots correspond to when $\omega R C=1$ for situations where charge separation (capacitance, $C$ ) and charge transfer (resistance, $R$ ) are in parallel, with $\omega$ the frequency of the voltage perturbation in radians.

Spectra at $-0.7 \mathrm{~V}$ are all similar, the in situ deposited bismuth film having the highest impedance while the bare carbon film has the lowest values. Differences between film formation methods become more apparent at $-1.0 \mathrm{~V}$, probably reflecting the beginning of a tiny amount of hydrogen evolution.

At $-1.4 \mathrm{~V}$, where hydrogen evolution is beginning to become more significant in acetate buffer solution, the 
impedance values are, consequently, much lower. The films formed at constant applied potential, ex situ and in situ, give an almost coincident response due to their similarity and the highest impedance values. Bismuth films deposited galvanostatically or by potential cycling have spectra significantly different from the films formed at constant potential.

The plots of $Z$ " vs. $\lg f$ conveniently show the different time constants of the processes occurring at both $-1.0 \mathrm{~V}$ and at $-1.4 \mathrm{~V}$. At $-1.0 \mathrm{~V}$ those of the films obtained by potential cycling and galvanostatically are the same, and bismuth films formed at constant potential approximate to those of the bare carbon film. The peaks move to much higher frequency values at $-1.4 \mathrm{~V}$, mainly due to more facile charge transfer, being coincident at $\lg f=1.3$ for films formed at constant applied potential and are also the same at $\lg f=2.0$ for the other bismuth films and the bare carbon electrode. This suggests that potential cycling and galvanostatic deposition lead to bismuth films with some similar characteristics to the bare carbon film.

Equivalent electrical circuits for modelling comprised the cell resistance, $R_{\Omega}$, which was ca. $20 \Omega \mathrm{cm}^{2}$ in all cases, in series with one or two $R C P E$ parallel combinations. The first of these, corresponding to that at higher frequency, consists of the charge transfer resistance, $R_{\mathrm{ct}}$, at the electrodesolution interface and the CPE models a non-ideal capacitor, according to:

$\mathrm{CPE}=1 /(C \mathrm{i} \omega)^{\alpha}$

This was sufficient to model the spectra at $-1.4 \mathrm{~V}$, since hydrogen evolution was the dominant process. At the more positive values of applied potential the second $R C P E$

Table 1. Parameters from equivalent circuit fitting of the high frequency part of impedance spectra of Figure $2 . R_{\mathrm{ct}}$ : charge transfer resistance, $C_{1}$ : capacitance, $\alpha_{1}$ : roughness exponent.

\begin{tabular}{llll}
\hline$E$ (V vs. SCE) & $\begin{array}{l}R_{\mathrm{ct}} \\
\left(\mathrm{k} \Omega \mathrm{cm}^{2}\right)\end{array}$ & $\begin{array}{l}C_{1} \\
\left(\mu \mathrm{F} \mathrm{cm} \mathrm{cm}^{-2}\right)\end{array}$ & $\alpha_{1}$ \\
\hline Carbon film & & & \\
-0.7 & 3.21 & 43.0 & 0.87 \\
-1.0 & 3.20 & 27.7 & 0.88 \\
-1.4 & 0.34 & 17.4 & 0.85 \\
Bi film - constant potential ex situ & & & \\
-0.7 & 47.1 & 130 & 0.85 \\
-1.0 & 2.46 & 24.6 & 0.93 \\
-1.4 & 0.81 & 15.2 & 0.87 \\
Bi film - constant potential in situ & & & \\
-0.7 & 10.5 & 41.1 & 0.79 \\
-1.0 & 18.3 & 17.4 & 0.86 \\
-1.4 & 0.82 & 17.2 & 0.86 \\
Bi film - potential cycling & & & \\
-0.7 & 102 & 187 & 0.62 \\
-1.0 & 11.6 & 114 & 0.66 \\
-1.4 & 0.13 & 75.6 & 0.74 \\
Bi film - constant applied current & & & \\
-0.7 & 82.1 & 128 & 0.63 \\
-1.0 & 13.2 & 92.6 & 0.66 \\
-1.4 & 0.18 & 60.2 & 0.72 \\
\hline
\end{tabular}

Electroanalysis 2005, 17, No. $15-16$ parallel element was necessary, since the properties of the carbon/bismuth film were comparable with those of the interface. Table 1 shows data from the "high frequency" loop. The more negative potential leads to lower values of capacity as well as to lower charge transfer resistances. Of particular interest is the CPE exponent $\alpha$, which is much lower for the films formed by potential cycling and galvanostatically or the bare carbon film. It suggests that the surface is rougher and may not be completely covered by bismuth, as also indicated from the $Z^{\prime \prime}$ vs. $\lg f$ plots - this would explain the less negative potential limit. Impedance is thus an extremely useful tool for aiding in elucidating these phenomena.

\subsection{Determination of $\mathrm{Zn}, \mathrm{Cd}$, and $\mathrm{Pb}$ by Anodic Stripping Voltammetry}

The bismuth film electrodes prepared by different ways developed in this work were evaluated for the measurement of zinc(II), cadmium(II) and lead(II) by SWASV. An example of typical experimental traces is given in Figure 3 and a summary of the calibration plot data obtained is in Table 2.

It has been found by other authors $[1,3,4,8,10,16]$ that in situ deposited bismuth films are more sensitive to some heavy metals than films of mercury or bismuth deposited ex situ. In order to increase the sensitivity of ex situ deposited films, bromide ion, which increases the homogeneity of the bismuth film according to [29], was added to the deposition solution in $[11,13]$. However, with carbon film substrates it was found that ex situ deposited bismuth films had almost the same sensitivity as the in situ, as shown in Table 2, and thence essentially the same homogeneity. This occurred despite the fact that a lower $\mathrm{Bi}^{3+}$ concentration was used for in situ deposition, following the optimized procedure described in [1], than in the predeposition case which used a $>2$ times higher bismuth concentration and a deposition time ca. 3 times longer.

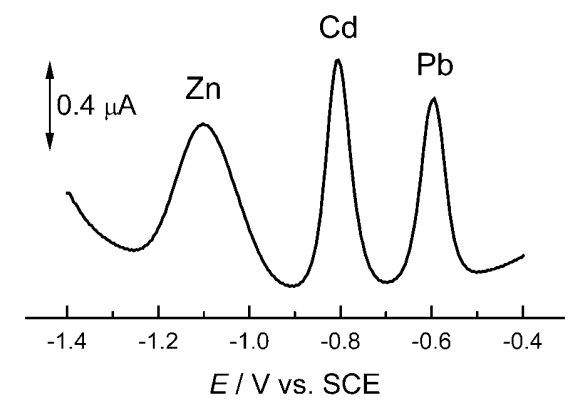

Fig. 3. Square-wave anodic stripping voltammograms of $10 \mu \mathrm{g}$ $\mathrm{L}^{-1}$ metal ions (154 $\mathrm{nM} \mathrm{Zn,} 89 \mathrm{nM} \mathrm{Cd}$, and $\left.48 \mathrm{nM} \mathrm{Pb}\right)$ at bismuth film deposited in situ. Preconcentration potential $-1.4 \mathrm{~V}$, preconcentration time $120 \mathrm{~s}$. Supporting electrolyte $0.1 \mathrm{M}$ acetate buffer, $\mathrm{pH}$ 4.45. Measurement conditions: frequency $25 \mathrm{~Hz}$, step potential $4 \mathrm{mV}$, amplitude $25 \mathrm{mV}$, equilibration time $15 \mathrm{~s}$. 
Table 2. Calibration plot data from SWASV experiments of $\mathrm{Cd}(\mathrm{II}), \mathrm{Zn}(\mathrm{II})$ and $\mathrm{Pb}(\mathrm{II})$ at in situ and ex situ deposited bismuth films.

\begin{tabular}{|c|c|c|c|c|c|}
\hline Bismuth film preparation & Analyte & Linear range $(\mathrm{nM})$ & $\begin{array}{l}\text { Slope } \\
\left(\mathrm{nA} \mathrm{nM}^{-1}\right)\end{array}$ & $\begin{array}{l}\text { Intercept } \\
(\mathrm{nA})\end{array}$ & $\begin{array}{l}\text { LOD } \\
(\mathrm{nM})\end{array}$ \\
\hline \multirow[t]{3}{*}{ Constant potential in situ } & $\mathrm{Zn}(\mathrm{II})$ & $40-600$ & $2.41 \pm 0.11$ & $-4.77 \pm 2.74$ & 1.30 \\
\hline & $\mathrm{Cd}(\mathrm{II})$ & $50-350$ & $0.42 \pm 0.02$ & $-3.06 \pm 0.54$ & 7.31 \\
\hline & $\mathrm{Pb}(\mathrm{II})$ & $20-200$ & $3.74 \pm 0.12$ & $-5.10 \pm 0.94$ & 0.79 \\
\hline \multirow[t]{3}{*}{ Constant potential ex situ } & $\mathrm{Zn}(\mathrm{II})$ & $70-600$ & $0.23 \pm 0.02$ & $10.5 \pm 6.9$ & 2.12 \\
\hline & $\mathrm{Cd}(\mathrm{II})$ & $40-350$ & $3.04 \pm 0.08$ & $18.2 \pm 9.3$ & 1.05 \\
\hline & $\mathrm{Pb}(\mathrm{II})$ & $20-200$ & $3.74 \pm 0.15$ & $-26.9 \pm 9.8$ & 0.63 \\
\hline \multirow[t]{3}{*}{ Potential cycling } & $\mathrm{Zn}(\mathrm{II})$ & - & - & - & - \\
\hline & $\mathrm{Cd}(\mathrm{II})$ & $15-75$ & $1.98 \pm 0.18$ & $-16.9 \pm 7.7$ & 1.67 \\
\hline & $\mathrm{Pb}(\mathrm{II})$ & $10-50$ & $4.62 \pm 0.23$ & $-2.85 \pm 0.64$ & 0.71 \\
\hline \multirow[t]{3}{*}{ Galvanostatic } & $\mathrm{Zn}(\mathrm{II})$ & $750-4600$ & $0.78 \pm 0.20$ & $-46.6 \pm 14.6$ & 138.5 \\
\hline & $\mathrm{Cd}(\mathrm{II})$ & $90-2500$ & $0.32 \pm 0.01$ & $-4.20 \pm 1.13$ & 41.1 \\
\hline & $\mathrm{Pb}(\mathrm{II})$ & $50-1500$ & $0.15 \pm 0.02$ & $-2.61 \pm 0.23$ & 18.8 \\
\hline
\end{tabular}

Both the peak current and potential vary with concentration for $\mathrm{Zn}, \mathrm{Cd}$ and $\mathrm{Pb}$ at bismuth film electrodes. At low concentrations, the peak current increases proportionally with concentration up to $40 \mu \mathrm{g} \mathrm{\textrm {L } ^ { - 1 }}$ of each metal ion (i.e., $615 \mathrm{nM} \mathrm{Zn,} 357 \mathrm{nM} \mathrm{Cd}$, and $192 \mathrm{nM} \mathrm{Pb}$ ) and the peak potential does not change for $\mathrm{Zn}(-1.06 \mathrm{~V})$, but shifts to less negative potential values for $\mathrm{Cd}$ (from -0.81 to $-0.79 \mathrm{~V}$ ) and $\mathrm{Pb}$ (from -0.63 to $-0.60 \mathrm{~V}$ vs. SCE). Other data in these linear ranges are presented in Table 2. At higher concentrations the calibration plot slope increased and a second linear range was found up to $300 \mu \mathrm{g} \mathrm{L}^{-1}$ of each metal ion. However, this part of the analytical plots was not of primary interest and had a large non-zero intercept. As can be deduced from the shift of the peak potential and the slightly negative intercepts in the calibration plots (Table 2), all three metals form a kind of intermediate intermetallic complex compound, as previously found at $\mathrm{Bi}_{2} \mathrm{O}_{3}$ modified carbon paste electrodes [18]. The weakest of these occur with $\mathrm{Pb}$ and the strongest with $\mathrm{Zn}$ as deduced from the dependence of the peak potential shift on metal ion concentration.

Surprisingly, a high sensitivity was obtained at bismuth films deposited by cycling of the applied potential, see Table 2, although they exhibited non-zero intercepts and this film gave no response to $\mathrm{Zn}(\mathrm{II})$, presumably owing to competitive hydrogen evolution.

The reproducibility of SWASV at a particular carbon film electrode was determined by forming a bismuth film and applying it to the anodic stripping analysis of the metals mentioned above, repeating the whole process five times. The results obtained $(n=5)$ were better at bismuth deposited in situ (except for $\mathrm{Zn}$ ), where the reproducibility was $96.9-98.8 \%$ than at the ex situ deposited films where it was $87.4-95.4 \%$. The least good reproducibility was for $\mathrm{Zn}$ at in situ deposited films, probably caused by some small hydrogen evolution at the preconcentration potential, $-1.4 \mathrm{~V}$ (vs. SCE); at the bismuth films deposited ex situ reproducibility was much better since the hydrogen overpotential was higher such that hydrogen evolution was negligible.

Detection limits at these electrodes were lower than or similar to those obtained at bismuth films deposited at constant potential reported in the literature, e.g., $[10,12,16]$. Additionally, most of them used a longer preconcentration time. Except for galvanostatically-formed BiFEs these were of the order of $1 \mathrm{nM}$, which makes the method a useful tool for application in natural samples, even after sample dilution with electrolyte. This is promising for future application of these robust and cost-effective electrodes outside the laboratory.

\section{Conclusions}

Bismuth film electrodes, formed by bismuth deposition in different ways on carbon film resistor electrodes, were characterized voltammetrically and by electrochemical impedance spectroscopy. Bismuth films deposited galvanostatically and by potential cycling were studied for the first time. BiFEs prepared in different ways were applied to the determination of trace $\mathrm{Zn}, \mathrm{Cd}$, and $\mathrm{Pb}$ ions. The in situ deposited films exhibited the best reproducibility, except for $\mathrm{Zn}$ determination, than the predeposited ones, and sensitivity was similar at both in situ and ex situ deposited bismuth films. The highest sensitivity for lead together with a low sub-nanomolar detection limit was found at bismuth films deposited by cycling of the applied potential. These results point to future application of these bismuth film sensors for disposable or short-term use.

\section{Acknowledgements}

Financial support from Fundação para a Ciência e a Tecnologia (FCT), ICEMS (Research Unit 103), Portugal, is gratefully acknowledged. R. Pauliukaite thanks FCT for a postdoctoral fellowship (SFRH/BPD/14518/2003).

\section{References}

[1] J. Wang, J. Lu, S. B. Hocevar, P. A.M. Farias, B. Ogorevc, Anal. Chem. 2000, 72, 3218.

(C) 2005 WILEY-VCH Verlag GmbH \& Co. KGaA, Weinheim 
[2] J. Wang, J. Lu, Electrochem. Commun. 2000, 2, 390.

[3] J. Wang, R. P. Deo, S. Thongngamdee, B. Ogorevc, Electroanalysis 2001, 13, 1153.

[4] J. Wang, J. Lu, Ü. A. Kirgös, S. B. Hocevar, B. Ogorevc, Anal. Chim. Acta 2001, 434, 29.

[5] J. Wang, Ü. A. Kirgös, J. Lu, Electrochem. Commun. 2001, 3, 703.

[6] E. A. Hutton, B. Ogorevc, S. B. Hocevar, F. Weldon, M. R. Smyth, J. Wang, Electrochem. Commun. 2001, 3, 707.

[7] S. B. Hocevar, J. Wang, R. P. Deo, B. Ogorevc, Electroanalysis 2002, 14, 112.

[8] S. B. Hocevar, B. Ogorevc, J. Wang, B. Pihlar, Electroanalysis 2002, 14, 1707.

[9] E. A. Hutton, S. B. Hocevar, B. Ogorevc, M. R. Smyth, Electrochem. Commun. 2003, 5, 765.

[10] G. Kefala, A. Economou, A. Voulgaropoulos, M. Sofoniou, Talanta 2003, 61, 603.

[11] A. Krolicka, A. Bobrowski, K. Kalcher, J. Mocak, I. Svancara, K. Vytras, Electroanalysis 2003, 15, 1859.

[12] C. E. Banks, J. Kruusma, M. E. Hyde, A. Salimi, R. G. Compton, Anal. Bioanal. Chem. 2004, 379, 277.

[13] A. Krolicka, A. Bobrowski, Electrochem. Commun. 2004, 6, 99.

[14] J. Wang, J. Lu, S. B. Hocevar, B. Ogorevc, Electroanalysis 2001, 13, 13.

[15] R. O. Kadara, I. E. Tothill, Anal. Bioanal. Chem. 2004, 378, 770.

[16] K. Vytřas, I. Švancara, R. Metelka, Electroanalysis 2002, 14, 1359.

[17] A. Królicka, R. Pauliukaitè, I. Evancara, R. Metelka, A. Bobrowski, E. Norkus, K. Kalcher, K. Vytřas, Electrochem. Commun. 2002, 4, 193.

[18] R. Pauliukaitè, R. Metelka, I. Švancara, A. Królicka, A. Bobrowski, K. Vytřas, E. Norkus, K. Kalcher, Anal. Bioanal. Chem. 2002, 374, 1155.

[19] C. E. Banks, J. Kruusma, R. R. Moore, P. Tomćik, J. Peters, J. Davis, Š. Komorsky-Lovrić, R. G. Compton, Talanta 2005, 65, 423.
[20] G. U. Flechsig, O. Korbout, S. B. Hocevar, S. Thongngamdee, B. Ogorevc, P. Gründler, J. Wang, Electroanalysis 2002, 14, 192.

[21] R. Pauliukaite, S. B. Hočevar, B. Ogorevc, J. Wang, Electroanalysis 2004, 16, 719.

[22] E. A. Hutton, J. T. van Elteren, B. Ogorevc, M. R. Smyth, Talanta 2004, 63, 849.

[23] Z. Guo, F. Feng, Y. Hou, N. Jaffrezic-Renault, Talanta 2004, 65,1052 .

[24] D. Demtriades, A. Economou, A. Voulgaropoulos, Anal. Chim. Acta 2004, 519, 167.

[25] L. Lin, N. S. Lawrence, S. Thongngamdee, J. Wang, Y. Lin, Talanta 2005, 65, 144.

[26] M. Morfobos, A. Economou, A. Voulgaropoulos, Anal. Chim. Acta 2004, 519, 57.

[27] E. A. Hutton, B. Ogorevc, M. R. Smyth, Electroanalysis 2004, 16, 1616.

[28] E. Chatzitheodorou, A. Economou, A. Voulgaropoulos, Electroanalysis 2004, 16, 1745.

[29] I. Svancara, L. Baldrianova, M. Vlcek, R. Metelka, K. Vytras, Electroanalysis 2005, 17, 120.

[30] C. M. A. Brett, L. Angnes, H.-D. Liess, Electroanalysis 2001, 13,765 .

[31] O. M. S. Filipe, C. M. A. Brett, Electroanalysis 2004, 16, 994.

[32] C. Gouveia-Caridade, C. M. A. Brett, Electroanalysis 2005, $17,549$.

[33] O. M. S. Filipe, C. M. A. Brett, Talanta 2003, 61, 643.

[34] R. Pauliukaite, M. E. Ghica, C. M. A. Brett, Anal. Bioanal. Chem. 2005, 381, 972.

[35] R. Pauliukaite, M. Florescu, C. M. A. Brett, J. Solid State Electrochem., in press.

[36] M. Florescu, C. M. A. Brett, Anal. Lett. 2004, 37, 871.

[37] M. Florescu, C. M. A. Brett, Talanta 2005, 65, 306.

[38] M. E. Ghica, C. M. A. Brett, Anal. Chim. Acta 2005, 532, 145.

[39] J. J. O'Dea, J. Osteryoung, R. A. Osteryoung, J. Phys. Chem. $\mathbf{1 9 8 3}, 87,3911$. 